\title{
Potensi Estrak Daun Miana (Coleus atropurpureus) Menghambat Pertumbuhan Malassezia furfur pada Penderita Pityriasis versicolor
}

\author{
Anita Rahmawati, Effendy Rasiyanto \\ Program Studi Laboratorium Medis, Politeknik Kesehatan Muhammadiyah, Makassar \\ Correspoding Author e-mail: anitadinar1983@gmail.com
}

\begin{abstract}
Background: Pitryasis versicolor is one of the fungal infections of the skin caused by the fungus Malassezia furfur often infecting residents in tropical climates due to the temperature and humidity suitable for the growth of the fungus, so an alternative drug is needed such as herbs such as miana leaves which contain plants flavonoids, saponins, steroids, tannins, essential oils, eugenol, polyphenol compounds, alkaloids, ethyl salicylates, calcium oxalate, and rosmarinic acid (RA) compounds.Pusrpose: The purpose of this study was to determine the antifungal potential of miana leaf extract against Malassezia furfur fungi isolated from patients with Pitryasis versicolor (Panu). Method: This type of research is a laboratory experiment with the paper disk method. Result: The research results obtained from the inhibitory test were Miana leaf extract with a concentration of 250 $\mathrm{mg} / \mathrm{ml}, 125 \mathrm{mg} / \mathrm{ml}, 62.5 \mathrm{mg} / \mathrm{ml}, 31.25 \mathrm{mg} / \mathrm{ml}$, and $15.625 \mathrm{mg} / \mathrm{ml}$, with the diameter of each inhibition zone $0.00 \mathrm{~mm}$. Conclusion: From the results of the study it can be concluded that miana leaf extract does not have the potential to inhibit the growth of Malassezia furfur fungus due to Tinea versicolor.
\end{abstract}

Keywords: inhibition test, Malassezia furfur, Pitryasis versicolor

\section{PENDAHULUAN}

Indonesia merupakan negara yang beriklim tropis, sehingga penduduknya sangat rentan terkena infeksi jamur (mikosis) pada kulit karena suhu yang hangat dan kelembapannya yang tinggi, kondisi ini merupakan lingkungan yang sesuai untuk pertumbuhan jamur. Sebagaian besar infeksi jamur pada kulit disebabkan oleh jamur dari golongan Tricophyton dan Microsporum dengan bentuk infeksi berupa Tinea pedis, Tinea ungium, Tinea capitis, dan Pityriasis verscolor (Amiruddin, 2010).

$$
\text { Pityriasis versicolor (panu) }
$$

adalah suatu infeksi kronis superfisial yang ringan pada stratum korneum (lapisan terluar kulit) yang disebabkan oleh Malassezia furfur, yaitu jamur yang bersifat lipofilik dimorfik dan merupakan flora normal pada kulit manusia, ditandai dengan bercak lesi yang bervariasi mulai dari hipopigmentasi, kemerahan sampai kecoklatan atau hiperpegmentasi pada kulit, biasanya pada dada, punggung atas, lengan atau perut. Lesinya kronis dan terjadi sebagai bercak-bercak macular (daerah kecil yang berbentuk bulat) pada kulit yang berbeda warna yang bias membesar dan bergantung, peradangan dan iritasi minimal.

Malaszia furfur adalah ragi lipofilik yang membutuhkan lipid untuk media pertumbuhan. Diagnostik dipastikan dengan pemeriksaan mikroskopik dari kerokan kulit yang terinfeksi ditambah dengan $\mathrm{KOH} 20 \%$ atau diwarnai dengan Calcaflour white. Terlihat hifa pendek,tak bercabang dan sel-sel bulat. Lesi juga berpendar di bawah lampu wood. Pityriasis versicolor diobati dengan pemberian selenium sulfide setiap hari. Azole-azole oral atau topikal juga efektif (Brooks et al, 2005). 
Indonesia memiliki banyak jenis tanaman yang dapat dibudidayakan karena memiliki manfaat yang besar bagi manusia dalam hal pengobatan. Dalam tanaman ada banyak komponen kimia yang dapat digunakan sebagai obat. Pada saat ini banyak orang yang kembali menggunakan bahan-bahan alam yang dalam pelaksanaannya membiasakan hidup dengan menghindari bahan-bahan kimia sintesis dan lebih mengutamakan bahanahan alami (Amiruddin, 2010).

Beberapa kajian farmakologi telah dilakukan yang menunjukkan bahwa daun Miana (Coleus atroporpereus) berkhasiat sebagai imunostimulan (Pakadang et al. 2015), antibakteri (Kumala, et al. 2009; Mpila, et al. 2012; Yuningsih 2007; Rahmawati 2008), antikanker (Sulaiman 2006), antiinflamasi dan antihiperglikemia (Illyyani, et al. 2015). Namun kajian farmakologi untuk khasiatnya dalam menanggulangi fungi masih sedikit, meskipun secara in vitro telah terbukti yaitu anticandida pada Candida tropicalis (Nazula 2013) dan Candida albicans (Dwi, 2014).

Beberapa studi tentang senyawa aktif antimikrobial daun miana (Coleus atropurpereus) yaitu berupa flavonoid, saponin, steroid, tanin, minyak atsiri, eugenol, senyawa polifenol, alkaloid, etil salisilat, kalsium oksalat, senyawa rosmarinic acid (RA) (Nugroho \&Yunastuti, 2009).

Berdasarkan latar belakang di atas maka perlu dilakukan penelitian dengan memanfaatkan bahan-bahan alami yang mengandung senyawa kimia. Oleh karena itu peneliti ingin mengetahui uji daya hambat ekstrak daun miana (Coleus atropurpereus) terhadap Malassezia furfur yang diisolasi dari penderita Pityriasis versicolor.

\section{METODE}

Jenis penelitian adalah eksperimen laboratorik dengan metode difusi untuk mengetahui potensi antifungi ekstrak daun miana terhadap Malassezia furfur yang diisolasi dari penderita Pityriasis versicolor. Penelitian ini dilaksanakan di Laboratorium Mikrobiologi Politeknik Kesehatan Muhammaddiyah Makassar Prodi D-III Teknologi Laboratorium Medis pada 4-16 April 2019.

Populasi daripenelitian ini adalah daun miana (Coleus atroporpereus) yang telah diekstrak diambil dari daerah sekitar kota Makassar. Sampel dari penelitian ini adalah ekstrak daun miana yang diambil dengan konsentrasi250 $\mathrm{mg} / \mathrm{mL}, 125$ $\mathrm{mg} / \mathrm{mL}, 62,5 \mathrm{mg} / \mathrm{mL}, 31,25 \mathrm{mg} / \mathrm{mL}$, dan $15,625 \mathrm{mg} / \mathrm{mL}$. Teknik pengambilan sampel adalah secara accidental sampling

Alat yang digunakan dalam percobaan ini adalah botol steril, cawan petri, pencadang, tabung reaksi, rak tabung, lampu spiritus, korek api, pinset, ose, swab, timbangan analitik, beaker glas, sendok tanduk, batang pengaduk, Erlenmeyer, hot plate, penggaris, spidol, auto clave, oven, kapas, labu ukur, micropipete. Bahan yang digunakan dalam penelitian adalah $\mathrm{KOH} 10 \%$, aquadest, DMSO, biakan jamur Malassezia furfur, ekstrak daun miana, $500 \mathrm{mg}$ obat chloramphenicol, obat ketokonazol 500 mg, $\mathrm{BaCl}_{2} 1 \%$ dan $\mathrm{H}_{2} \mathrm{SO}_{4} 1 \%$,etanol $96 \%$ dan PDA (Potato Dextrose Agar). 


\section{Pembuatan media PDA (Potato Dextrose} Agar)

Dalam penelitian ini menggunakan media Potato Dextrose Agar (PDA) bahan medium ditimbang sebanyak 5,265 gram, selanjutnya dimasukkan ke dalam Erlenmeyer dan ditambahkan aquadest sebanyak $120 \mathrm{ml}$. Selanjutnya untuk mencegah kontaminasi bakteri ditambahkan $500 \mathrm{mg}$ chloramphenicol, kemudian ditutup dengan kapas dan dilarutkan di atas hot plate, kemudian disterilkan dalam autoclave pada suhu $121^{\circ} \mathrm{C}$ selama 15 menit (Kidd et al, 2016).

\section{Pembuatan Larutan Mac Farland 0,5\%}

Larutan baku Mac Farland terdiri atas 2 komponen, yaitu larutan $\mathrm{BaCl}_{2} 1 \%$ dan $\mathrm{H}_{2} \mathrm{SO}_{4} \quad 1 \%$. Larutan $\mathrm{BaCl}_{2} \quad 1 \%$ sebanyak $0,05 \mathrm{~mL}$ dicampur dengan larutan $\mathrm{H}_{2} \mathrm{SO}_{4} 1 \%$ sebanyak $9,95 \mathrm{ml}$ dalam labu ukur takar hingga homogen. Suspense ini digunakan sebagai larutan standar pembanding kekeruhan suspense jamur uji (Widiyanti dan Amran, 2018).

\section{Pembuatan larutan Kontrol Positif}

Kontrol positif yang digunakan yaitu obat Ketokonazol. Dibuat dengan cara ketokonazol 500 mg ditambahkan 10 mL aquadest.

\section{Persiapan sampel dan maserasi}

Daun miana (Coleus atropurpereus) yang telah dikumpulkan dibersihkan dari pengotor, selanjutnya dicuci di bawah air mengalir sampai bersih, ditiriskan, kemudian dikeringkan anginkan selama 5 hari. Daun miana (Coleus atropurpereus) yang telah kering direndam dengan etanol $96 \%$ selama 7 hari yang selanjutnya akan dilakukan rotavapor. Dilakukan pengadukan setiap hari selama 7 hari perendaman dan selanjutnya kan dilkukan rotavapor.

\section{Pembuatan konsentrasi}

Ekstrak hasil rotavapor sebanyak $2500 \mathrm{mg}$ kemudian dibuat konsentrasi dilakukan menggunakan rumus pengenceran yaitu:

$$
\mathrm{M} 1 . \mathrm{V} 1=\mathrm{M} 2 . \mathrm{V} 2
$$

Sehingga didapatkan konsentrasi 250 $\mathrm{mg} / \mathrm{ml}$ (daun miana murni yang telah diekstrak sebanyak $10 \mathrm{~mL}$ ), konsentrasi $125 \mathrm{mg} / \mathrm{mL}$ (2,5 $\mathrm{mL}$ dari konsentrasi 250 $\mathrm{mg} / \mathrm{ml}$ ekstrak daun miana dilarutkan dengan 2,5 mL aquadest), konsentrasi 62,5 $\mathrm{mg} / \mathrm{mL}(2,5 \mathrm{~mL}$ dari konsentrasi $80 \%$ ekstrak daun miana dilarutkan dengan 2,5 $\mathrm{mL}$ aquadest), konsentrasi $31,25 \mathrm{mg} / \mathrm{mL}$ (2,5 mL dari konsentrasi 62,5 ekstrak daun miana dilarutkan dengan 2,5 $\mathrm{mL}$ aquadest) dan konsentrasi $15,625 \quad(2,5 \mathrm{~mL}$ dari konsentrasi 31,25 $\mathrm{mg} / \mathrm{mLekstrak}$ daun miana dilarutkan dengan 2,5 $\mathrm{mL}$ aquadest).

\section{Isolasi jamur}

Beberapa bagian kulit yang akan dikerok dengan terlebih dahulu dihapus beberapa kali dengan kapas yang telah dibasahi alkohol 70\%, bagian kulit yang dikerok, sebaiknya bagian pinggir lesi yang aktif dan tertutup sisik kemudian perlahan-lahan bagian tersebut dikerok dengan menggunakan pisau tumpul/skalpel atau objek gelas, kerokan kulit ditampung dengan menggunakan cawan petri steril dan siap dipakai untuk pemeriksaan.

Isolasi awal jamur Malassezia furfur yakni skuama digores pada medium 
agar Sabaroud dekstrosa pada tabung atau cawan petri dan diinkubasi pada suhu $37^{\circ} \mathrm{C}$.dilakukan pengamatan pertumbuhan koloni jamur setiap hari sampai hari ke-7. Hasil positif jika terbentuk koloni berwarna krem mengkilat (Hayati, 2013).

\section{Peremajaan}

Dari sekian koloni yang tumbuh, dipilih satu koloni terbesar atau yang tampilan makroskopisnya dianggap mewakili koloni terbanyak dan digunakan sebagai bahan isolasi jamur yang akan diidentifikasi. (Hayati, 2013).

\section{Pemeriksaan Mikroskopis Malassezia furfur}

Identifikasi spesies Malassezia furfur dengan gambaran morfologi yakni dilakukan pengamatan morfologi makroskopis koloni Malassezia furfur yang tumbuh pada agar Sabaroud dekstrosa. Pemeriksaan makroskopis dilakukan dengan pemeriksaan langsung dengan larutan $\mathrm{KOH} 10 \%$. Diteteskan larutan $\mathrm{KOH} 10 \%$ pada kaca benda, dipanaskan ose ke lampu spiritus, ujung ose dibasahi dengan larutan $\mathrm{KOH} 10 \%$ kemudian, diambil spesimen menggunakan ose, specimen diletakkan pada tetesan larutan $\mathrm{KOH} 10 \%$ kemudian ditutup dengan kaca penutup, dilewatkan sediaan tersebut beberapa kali diatas nyala api, periksa dibawah mikroskop (Hayati, 2013).

\section{Pembuatan suspensi jamur}

Biakan jamur Malassezia furfur yang sudah diremajakan diambil seujung mata ose dan disuspensi pada $\mathrm{NaCl}$ fisiologis kemudian dibuat kekeruannya dibandingkan dengan standar Mac Fraland 0,5\% (Anonim, 2016).

\section{Penanaman pada medium}

Media PDA yang telah dingin ditambahkan dengan $1 \mathrm{~mL}$ suspensi jamur, kemudian menuang media PDA sebanyak $40 \mathrm{~mL}$ kedalam cawan petri, lalu dibiarkan memadat lalu diberikan label terhadap media yang ingin dipasangkan paperdisk dengan konsentrasi masing-masing, dilakukan perendaman paper disk pada ekstrak daun miana dengan masing-masing konsentrasi selama 30 menit dan meletakkan paper disk pada media yang telah memadat kemidian diinkubasi selama $2 \times 24$ jam dengan suhu $37^{\circ} \mathrm{C}$.

\section{Pembacaan/pengukuran diameter zona hambat}

Mengukur diameter zona hambat yang terjadi pada media agar plate menggunakan jangka sorong F. Diameter zona hambat yang diukur yaitu daerah jernih disekitar pencadang,diukur dari ujung satu keujung yang lain melalui sebanyak 2 kali dengan catatan yaitu pertumbuhan tips di atas zona hambat tidak perlu dipertahankan. Terbentuknya zona hambat yang ditandai dengan adanya daerah yang bening.

\section{Interpretasi hasil}

Terbentuknya zona hambat berwarna bening berbentuk lingkaran dan hitung zona hambatnya. Sebuah zona yang lebih besar dari kontrol positif menunjukkan zat uji aktif terhadap jamur, zona kecil mungkin berarti bahwa substansi itu hanya sedikit aktif terhadap jamur dan tidak ada zona mungkin berarti tidak ada kegiatan. 
Interpretasi aktifitas antifungi

Ketokonazole sebagai berikut (Karta dan Burhanuddin, 2017)

$\begin{array}{ll}\text { Resisten } & : \leq 12 \mathrm{~mm} \\ \text { Intermediate } & : 13-18 \mathrm{~mm} \\ \text { Sensitive } & : \geq 19 \mathrm{~mm}\end{array}$

Pada penelitian ini bahan uji yang digunakan adalah ekstrak daun miana (Coleus atroporpereus) dengan konsentrasi $250 \mathrm{mg} / \mathrm{ml}, 125 \mathrm{mg} / \mathrm{ml}, 62,5$ $\mathrm{mg} / \mathrm{ml}, 31,25 \mathrm{mg} / \mathrm{ml}$, dan $15,625 \mathrm{mg} / \mathrm{ml}$, yang diujikan daya hambatnya terhdap jamur Malassezia furfur yang diisolasi dari

\section{HASIL}

Tabel 1. Hasil pengukuran rata-rata zona daya hambat ektrak daun miana terhadap jamur Malassezia furfur

\begin{tabular}{ccccc}
\hline $\begin{array}{c}\text { Konsentarsi } \\
\text { Estrak (mg/ml) }\end{array}$ & $\begin{array}{c}\text { Replikasi } \\
\text { I }\end{array}$ & $\begin{array}{c}\text { Replikasi } \\
\text { II }\end{array}$ & $\begin{array}{c}\text { Replikasi } \\
\text { III }\end{array}$ & Total \\
\hline 250 & 0 & 0 & 0 & 0 \\
125 & 0 & 0 & 0 & 0 \\
62,5 & 0 & 0 & 0 & 0 \\
31,25 & 0 & 0 & 0 & 0 \\
15,62 & 0 & 0 & 0 & 0 \\
Kontrol negatif (akuades) & 0 & 0 & 0 & 0 \\
Kontrol poisitif (tetrasiklin) & 20 & 24 & 24 & 20,6 \\
\hline
\end{tabular}

(Sumber: Data primer)

penderita Pitiryasis versicolor (Panu). Direplikasi sebanyak 3 kali kemudian diinkubasi selama 48 jam pada suhu $37^{\circ} \mathrm{C}$ dan dilakukan pengukuran zona hambat dan hasilnya dilihat pada tabel 1 .

Berdasarkan tabel 1 dapat dilihat bahwa pada keseluruhan cawan petri dengan konsentrasi $250 \mathrm{mg} / \mathrm{ml}, 125$ $\mathrm{mg} / \mathrm{ml}, 62,5 \mathrm{mg} / \mathrm{ml}, 31,25 \mathrm{mg} / \mathrm{ml}$, dan $15,625 \mathrm{mg} / \mathrm{ml}$, keseluruhannya tidak menunjukkan adanya zona hambat yang terbentuk dengan rata-rata diameter masing-masing $\quad 0,00 \quad \mathrm{~mm}$ yang menandakan ekstrak daun miana tidak dapat menghambat pertumbuhan jamur, kontrol negatif menunjukkan tidak terbentuk zona hambat dengan diameter 0,00 mm, serta kontrol positif berupa obat anti jamur ketokonazol dapat menghambat pertumbuhan jamur dengan diameter 24,5 $\mathrm{mm}, 26,5 \mathrm{~mm}$ dan $27 \mathrm{~mm}$ sehingga didapatkan rata-rata $26 \mathrm{~mm}$ yang menandakan bahwa jamur masih sensitif terhadap antibiotik.

\section{PEMBAHASAN}

Penelitian tentang uji daya hambatekstrak daun miana (Coleus atroporpereus) sebagai anti jamur terhadap Malassezia furfur dilakukan di Laboratorium Mikrobiologi Politeknik Kesehatan Muhammadiyah Makassar prodi D-III Teknologi Laboratorium Medik. Pengamatan hasil uji potensi ekstrak daun miana terhadap pertumbuhan Malassezia furfur dilakukan dengan melihat adanya zona hambat yang terjadi akibat mekanisme antifungi dalam menghambat pertumbuhan jamur.

Sampel pada penelitian ini adalah ekstrak daun miana dengan metode maserasi.Sebelumnya daun miana yang 
diambil pada pagi hari diangin-anginkan, dengan tujuan agar menghilangkan komponen air dalam daun miana. Setelah kering daun miana ini direndam dengan pelarut etanol $96 \%$ yang berfungsi sebagai pelarut yang akan melarutkan zat aktif yang terkandung dalam sampel, dan dibuat menjadi ekstrak kental dengan menggunakan rotavapor. Untuk membuat konsentrasi ekstrak daun miana digunakan pelarut DMSO.

Hasil yang didapatkan pada penelitian ini menunjukkan hasil yang negatif karena tidak terdapat zona hambat pada konsentrasi yang diberikan. Ekstrak daun miana belum mampu menghambat jamur Malassezia furfur. Hal itu ditunjukkan dengan tidak terbentuknya zona hambat pada konsentrasi $250 \mathrm{mg} / \mathrm{ml}$, $125 \mathrm{mg} / \mathrm{ml}, 62,5 \mathrm{mg} / \mathrm{ml}, 31,25 \mathrm{mg} / \mathrm{ml}$, dan $15,625 \mathrm{mg} / \mathrm{ml}$, yang bertentangan dengan Kontrol (+) yaitu ketokonazole yang mampu menghambat jamur Malasezia furfur.

Tumbuhannya koloni jamur pada kontrol (-) berupa aquadest menunjukkan bahwa larutan tersebut tidak mempengaruhi pertumbuhan jamur. Ketokonazol digunakan sebagai larutan kontrol (+) yang betujuan sebagai pembanding pengukuran zona hambat yang terbentuk. Ketokonazol dipilih karena merupakan salah satu jenis antijamur sintetik yang mempunyai spectrum luas dan bersifat fungistatik. Ketokonazol bekerja dengan cara mengganggu sintesis ergosterol yang merupakan komponen penting membran jamur.

Ketokonazole merupakan salah satu jenis antijamur sintetetik yang mempunyai spektrum luas dan bersifat fungistatik. Kotokonazole bekerja dengan cara mengganggu sintesis ergosterol yang merupakan komponen dari mebran jamur. Penggunakan ketokonazol menunjukkan perbedaan yang berbeda nyata terhadap penggunaan ekstrak daun miana untuk konsentrasi uji. Perbedaan ini dapat dilihat dari besarnya diameter zona hambat yang terbentuk pada media (Tabel 1).

Penelitian yang telah dilakukan Nur safitri (2019) bahwa ekstrak daun miana dapat menghambat pertumbuhan bakteri Escherichia coli yang sama dan dapat menghambat sangat kuat, mendandakan ekstrak daun miana dapat bereaksi dengan bakteri, tetapi tidak dengan jamur Malassezia furfur. Hal ini dapat disebabkan karena struktur dan dinding sel bakteri yang lebih tipis dari struktur dinding sel jamur dan jamur Malassezia furfur merupakan salah satu organisme lipofilik dimorfik yang komponen dinding selnya terdiri dari mannan, glukan, dan kitin (Kumala, 2009).

Kekuatan antijamur diklasifikasikan menjadi 4 kelompok Davis (1971) dalam Alawiyah et al (2016) yaitu lemah $(\leq 5 \mathrm{~mm})$, sedang $(6-10 \mathrm{~mm})$, kuat $(11-20 \mathrm{~mm})$ dan sangat kuat $(\geq 20$ $\mathrm{mm})$. Berdasarkan hasil pengamatan (Tabel 1) memperlihatkan bahwa ekstrak daun miana (Coleus atroporpereus) tidak dapat menghambat pertumbuhan jamur Malassezia furfur.

Zat antijamur yang memiliki kemampuan menghambat pertumbuhan jamur dipengaruhi oleh beberapa faktor antara lain: konsentrasi zat antijamur, jenis, jumlah, umur dan keadaan jamur, suhu, waktu kontak, sifat-sifat kimia dan fisik media pertumbuhan, seperti $\mathrm{pH}$, kadar air, nutrisi, serta jumlah komponen 
didalamnya (Fardiaz (1985) dalam Budiarti (2007)).

\section{SIMPULAN}

Dari hasil dan pembahasan maka dapat disimpulkan bahwa ekstrak daun miana (Coleus atroporpereus) tidak dapat menghambat pertumbuhan jamur Malassezia furfur dengan variasi konsentrasi $250 \mathrm{mg} / \mathrm{ml}, 125 \mathrm{mg} / \mathrm{ml}, 62,5$ $\mathrm{mg} / \mathrm{ml}, 31,25 \mathrm{mg} / \mathrm{ml}$, dan $15,625 \mathrm{mg} / \mathrm{ml}$. sedangkan ketokonazol sebagai control positif (+) mampu menghambat dengan zona hambat sebesar $26 \mathrm{~mm}$.

\section{SARAN}

Berdasarkan hasil penelitian yang dilakukan, penulis menyarankan untuk dilakukan penelitian terhadap penghambatan Malassezia furfur menggunakan konsentrsi yang lebih tinggi atau menggunakan tanaman obat yang lainnya yang memiliki sifat antijmur lebih tinggi dari pada daun miana (Coleus atroporpereus).

\section{DAFTAR PUSTAKA}

Amiruddin, D. M. 2010. Ilmu Penyakit Kulit. Lkis: Jogjakarta

Anonim, 2016.Panduan Praktikum Mikrobiologi.Fakultas

FarmasiUniversitas Sanata Dharma.

Brooks, Geo F., Butel, Janet S., Morse, Stephen A. 2005. MikrobiologiKedokteran Jilid 2. Salemba Medika: Jakarta.

Chairlan, Lestari, E\&Mahode. 2013. Pedoman Teknik Dasar UntukLaboratorium Kesehatan Edisi 2. Buku Kedokteran EGC: Jakarta..
Ditjen POM, 1986. Sediaun Galenik. Jakarta: Dapartemen Kesehatan RI.Halaman 10-11.

Ditjen POM, 2000. Parameter Standar Umum Ekstrak Tumbuhan Obat.Cetakan Pertama. Jakarta: Dapartemen Kesehatan RI.

Gandahusada\&Srisasi.(2009) Atlas Parasitologi Kedokteran. Jakarta:Buku Kedokteran

Hayati, I\&Handayani, Z. P. 2013.Identifikasi Jamur Malassezia Furfur PadaNelayan Penderita Penyakit Kulit di RT 09 Kelurahan Malabro Kota Bengkulu. Jurnal Gardian Vol. 10. No. 1 Januari 2014: 972975.

Illyyani S, Intannia D, Triyasmono L. Pengaruh Pemberian Ekstrak Etanol Tanaman Miana ( Coleus atropurpureus Benth ) Terhadap Penurunan Kadar Glukosa Darah Pada Tikus Putih Jantan yang Diinduksi Aloksan. J. Pharmascience. 2015;2:19

Kidd, S., Halliday, C., Alexiou, H\&Ellis, D. 2016. Desciptons Of Medical Fungi. Newstyle Printing: Australia. Karta, W. T.\&Burhanuddin. 2017. Uji Aktifitas Anti JamurEkstrak Akar Tanaman Bamu(Plumbago Zeylanica) Terhadap Pertumbuhan Jamur Trichopyton menthagrophytes Penyebab Kurap Pada Kulit. Jurnal Media Sains 1 (1): 23-31.

Kandowangko, Y. N. (2011). Kajian Etnobotami Tanaman Obat Oleh Masyarakat Kabupaten Bonebolango, Provinsi Gorontalo: Universitas Negeri Gorontalo

Kumala S, Pratiwi Ainun A.2009 Efek antimikroba dari Kapang Endofit 
Ranting Tanaman Biduri. Jurnal Farmasi Indonesia. 2014; Vol. 7, No. 2

Lenny, S. 2013. Structure Elucidation Of Flavonoid Compound From The Leaves Of Coleus Atropurpureus Benth Using 1D- AND 2D-NMR Techniques. The Malaysian Journal of Analytical Sciences.

Lewis, R. E. 2011. Current Concepts in Anttifungal

Pharmacology.MayoClinic

Proceedings. 26 (8): 805-817.

Nazula R.S, 2014. Aktivitas Ekstrak Daun Miana (Coleus scutellarioides [L] Benth) Sebagai Antifungi Candida tropicalis.

http://repository.ipb.ac.id/bitstream /handle/123456789/70459/G14nrs. pdf

Nugroho \& Yunastuti, 2009. Pembuatan Formula dan Uji Aktifitas Obat Anti Malaria Berbasis Buah Sirih Menggunakan Teknologi Vacum Drying. Badan Penelitian Dan Pengembangan DepartemenKesehatan.

Mpila, D. A. Fatimawali \& Wiyono, W. I. 2012.Uji Aktivitas Antibakteri Ekstrak Etanol Daun Mayana (Coleus atropurpureus L. Bent.) terhadap Staphylococcus aureus, E. coli, dan Pseudomonas aeruginosa secara In-Vitro.Program Studi Farmasi FMIPA UNSRAT Manado.95115

Pakadang, S.2014.Potensi Ekstrak Daun Miana (Coleus scutellarioides (L) Benth) Sebagai Imunomodulator Pada Tikus Model Yang Terinfeksi Mycobacterium tuberculosis, ADLN Perpustakaan Universitas Airlangga
Prayoga, E. 2013.Perbandingan Efek Daun Sirih Hijau (piper betle L.) dengan Metode Difusi Disk dan Sumuran terhadap pertumbuhan Bakteri (Staphylococus aureus).Universitas Islam Negeri Syarif Hidayatullah.Skripsi. Jakarta.

Prianto \& Juni L.A. 2008.Atlas Parasitologi Kedokteran. Jakarta: PTGramedia.

Rahmawati F, 2008. Isolasi dan Karakterisasi Senyawa Antibakteri Ekstrak Daun Miana (Coleus stecullariodes (L) Benth). Tesis. Sekolah PascaSarjana IPB.

Ridwan, 2010. Efektifitas Anticestoda Ektrak Daun Miana (Coleus blumei Bent) terhadap Cacing Hymenolapis microstoma padaMencit. Media Peternakan Vol .33. No.1, hlm 6-11.

Siregar, R.S. 2005. Penyakit Jamur Kulit. Jakarta: Buku Kedokteran.

Sutanto, Inge. 2008.Parasitologi Kedokteran. Jakarta: Balai penerbit FKUI.

Tansil, S. 2016. Ilmu Penyakit Kulit Dan Kelamin. Sagung Seto: Jakarta.

Tari\&Rudianto.2013.Uji Efek Daun Iler (Coleus atropurpureusL.

Benth.)Terhadap Penyembuhan Luka Insisi pada Kulit Kelinci (Orycfolagus cuniculus).Jurnal ebiomedik (eBM), vol. 1, no.1, hlm. 581-586 $56 \quad$ UIN Syarif Hidayatullah: Jakarta

Widiyanti, T\& Amran, P. 2018. Penuntun Praktikum Bakteriologi III. Akademi Analis Kesehatan Muhammadiyah. 